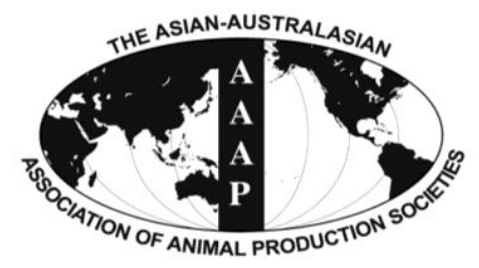

Asian Australas. J. Anim. Sci.

Vol. 26, No. 10 : 1484-1489 October 2013

http://dx.doi.org/10.5713/ajas.2013.13085

www.ajas.info

pISSN 1011-2367 elSSN 1976-5517

\title{
Effects of Chitosan on Body Weight Gain, Growth Hormone and Intestinal Morphology in Weaned Pigs
}

\author{
Yuanqing Xu, Binlin Shi*, Sumei Yan, Tiyu Li, Yiwei Guo, and Junliang Li \\ College of Animal Science, Inner Mongolia Agricultural University, Huhhot 010018, China
}

\begin{abstract}
The study was conducted to determine the effects of chitosan on the concentrations of GH and IGF-I in serum and small intestinal morphological structure of piglets, in order to evaluate the regulating action of chitosan on weaned pig growth through endocrine and intestinal morphological approaches. A total of 180 weaned pigs (35 d of age; $11.56 \pm 1.61 \mathrm{~kg}$ of body weight) were selected and assigned randomly to 5 dietary treatments, including 1 basal diet (control) and 4 diets with chitosan supplementation (100, $500,1,000$ and 2,000 mg/kg, respectively). Each treatment contained six replicate pens with six pigs per pen. The experiment lasted for $28 \mathrm{~d}$. The results showed that the average body weight gain (BWG) of pigs was improved quadratically by dietary chitosan during the former $14 \mathrm{~d}$ and the later $14 \mathrm{~d}$ after weaned $(\mathrm{p}<0.05)$. Furthermore, dietary supplementation of chitosan tended to quadratically increase the concentration of serum GH on $14(\mathrm{p}=0.082)$ and $28(\mathrm{p}=0.087)$. Diets supplemented with increasing levels of chitosan increased quadratically the villus height of jejunum and ileum on $\mathrm{d} 14(\mathrm{p}=0.089, \mathrm{p}<0.01)$ and $28(\mathrm{p}=0.074, \mathrm{p}<0.01)$, meanwhile, chitosan increased quadratically the ratio of villus height to crypt depth in duodenum, jejunum and ileum on $\mathrm{d} 14(\mathrm{p}<0.05, \mathrm{p}=0.055, \mathrm{p}<0.01)$ and 28 ( $<<0.01, \mathrm{p}<0.01, \mathrm{p}<0.01)$, however, it decreased quadratically crypt depth in ileum on $\mathrm{d} 14(\mathrm{p}<0.05)$ and that in duodenum, jejunum and ileum on $\mathrm{d} 28(\mathrm{p}<0.01, \mathrm{p}<0.05, \mathrm{p}<0.05)$. In conclusion, these results indicated that chitosan could quadratically improve growth in weaned pigs, and the underlying mechanism may due to the increase of the serum GH concentration and improvement of the small intestines morphological structure. (Key Words: Chitosan, Weaned Pig, GH, IGF-I, Small Intestine, Morphological Structure)
\end{abstract}

\section{INTRODUCTION}

Chitosan, a deacetylated chitin, is widespread in nature. The exoskeletons of arthropods such as crabs, shrimps, insects, and other marine creatures in the crustacean family are good sources of chitosan (Crini, 2005; Huang et al., 2007; Li et al., 2009). Chitosan is a natural alkaline polysaccharide with positive charges, and also one of the most abundant natural polymers (Knaul et al., 1999; Wang and Zhang, 2004; Xu and Wang, 2005). As a nontoxic, biodegradable carbohydrate polymer (Goiri et al., 2010), it contains amino and hydroxyl groups per residue (Liao et al., 2007), which give chitosan many biological activities, such as haemostatic (Pusateri et al., 2006), anti-inflammatory (Dai et al., 2009), antitumor activity (Tsukada et al., 1990; Koide, 1998), antimicrobial activity (Limam et al., 2011; Benhabiles et al., 2012), hypoglycemic and hypocholesterolemic activity (Yao et al., 2006, 2008) and an

\footnotetext{
* Corresponding Author: Binlin Shi. Tel: +86-471-430-8841, Fax: +86-471-431-3717, E-mail: shibinlin@ aliyun.com Submitted Feb. 4, 2013; Accepted Mar. 6, 2013; Revised May 9, 2013
}

immune-stimulatory effect (Moon et al., 2007; Yin et al., 2008).

Chitosan has become a new candidate as a growthpromoter for farm animals. Previous experiments involving piglets and broilers have demonstrated that chitosan improves growth performance of animals (Huang et al., 2005; Shi et al., 2005; Khambualai et al., 2009; Yuan and Chen, 2012). But the mechanism was not understood completely. Therefore, the present experiment was conducted to determine the effects of dietary chitosan supplementation on serum GH and IGF-1 and small intestinal morphological structure in weaned pigs.

\section{MATERIALS AND METHODS}

The protocol of the present experiment was approved by the Animal Care and Use Committee, Inner Mongolia Agricultural University, Huhhot, China.

\section{Animals and experimental design}

A total of 180 crossbred pigs (Duroc $\times$ Yorkshire $\times$ Landrace; average body weight of $11.56 \pm 1.61 \mathrm{~kg}$; $35 \mathrm{~d}$ of 
age) were used in this study. The pigs were weaned at $28 \mathrm{~d}$ of age. After weaning, the pigs were moved into the nursery building and given a 7-d adjustment period to adapt to the building and the dietary treatment. Pigs were randomly allotted to five treatments based on body weight and gender in a single factorial arrangement. Each treatment had 6 replicates (three replicate pens of males and three replicate pens of females) with 6 pigs per replicate. The five treatments were a basal diet (control group) and 4 diets with chitosan supplementation $(100,500,1,000$ and 2,000 mg/kg, respectively).

The basal diet met or exceeded nutrient requirements recommended by the NRC (1998) for swine and contained no chitosan (Table 1). The chitosan used in this experiment was provided by Jinan Haidebei Marine Bioengineering Co, Ltd. (Shandong Province, China) and its degree of deacetylation was determined to be $85.09 \%$, and viscosity to be 45 cps.

The pigs were housed in a temperature controlled room and plastic floored pens of $4.00 \times 4.20 \mathrm{~m}^{2}$ size with a selffeeder and nipple drinker to allow ad libitum access to feed and water. The environmental temperature was initially established at $28^{\circ} \mathrm{C}$, which gradually decline to $20^{\circ} \mathrm{C}$ by the

Table 1. Composition and nutrient levels of basal diets (air dry basis)

\begin{tabular}{lc}
\hline Ingredients & Content $(\%)$ \\
\hline Corn & 51.90 \\
Soybean meal & 16.00 \\
Wheat & 20.00 \\
Fish meal & 2.50 \\
Corn gluten meal & 2.00 \\
Whey powder & 2.00 \\
Soybean oil & 2.00 \\
Limestone & 0.70 \\
CaHPO & 1.00 \\
NaCl & 0.30 \\
Premix & 1.60 \\
Total & 100 \\
Nutrients & \\
$\quad$ Digestible energy $(\mathrm{MJ} / \mathrm{kg})$ & 14.32 \\
Crude protein $(\%)$ & 20.02 \\
Calcium $(\mathrm{Ca}, \%)$ & 0.72 \\
Phosphorus $(\mathrm{P}, \%)$ & 0.56 \\
Lysine $(\%)$ & 1.15 \\
\hline
\end{tabular}

${ }^{1}$ The premix provides following nutrients per $\mathrm{kg}$ diet: Vitamin A 9,000 IU; Vitamin $D_{3} 2,500$ IU; Vitamin E 60 IU; Vitamin $\mathrm{K}_{3} 4.5 \mathrm{mg}$; Vitamin $B_{1} 2.6 \mathrm{mg}$; Vitamin $B_{2} 8.7 \mathrm{mg}$; Vitamin $B_{6} 7.0 \mathrm{mg}$; Vitamin $B_{12} 0.03 \mathrm{mg}$; Pantothenic acid $13 \mathrm{mg}$; Nicotinic acid $35 \mathrm{mg}$; Biotin $0.47 \mathrm{mg}$; Folic acid $0.85 \mathrm{mg}$; Iron $(\mathrm{Fe}) 155 \mathrm{mg}$; Copper $(\mathrm{Cu}) 135 \mathrm{mg}$; Zinc (Zn) $100 \mathrm{mg}$; Manganese (Mn) $100 \mathrm{mg}$; Iodin (I) $0.35 \mathrm{mg}$; Cobalt (Co) $0.2 \mathrm{mg}$; Selenium (Se) $0.25 \mathrm{mg}$; Choline chloride $750 \mathrm{mg}$; Phytase 500 FTU.

${ }^{2}$ The energy was calculated from tabular value (NRC, 1998), and other nutrient compositions were analyzed. end of the experiment.

\section{Sampling and measurements}

Growth performance: The pigs were individually weighed at the start and on d 14 and 28 of the trial, and the average body weight gain (BWG) was calculated.

Blood sample: On d 14 and 28, peripheral blood was obtained through puncture of vena cava from one pig per pen and collected in a 5-mL evacuated tube (Becton Dickinson Vacutainer Systems, Franklin Lakes, NJ). Immediately after blood collection, the tubes were gently rocked several times and centrifuged $(1,200 \times \mathrm{g}$ for $15 \mathrm{~min})$. After centrifugation, serum samples were labeled and stored at $-80^{\circ} \mathrm{C}$ in cryogenic tubes until concentrations of $\mathrm{GH}$ and IGF-I were analyzed. The concentrations of GH and IGF-I were analyzed using commercially available RIA kits (Beijing Huaying Institute of Biological Technology, Beijing, China). All steps of the RIA for the serum GH and IGF-I were performed according to the kit protocol.

Small intestinal morphological structure: On d 14 and 28 of the experimental period, one pig was randomly selected from each pen and killed by intravenous injection of sodium pentobarbital. The gastrointestinal tracts were quickly removed, and approximately $2 \mathrm{~cm}$ segments of the duodenum, jejunum and ileum were taken from the middle of each part, cut transversely, washed with physiological saline and covered with tissue-tek O.C.T (Sakura finetek Japan Co., Ltd., Tokyo, Japan). The segments were cut approximately $7 \mu \mathrm{m}$ thick with a freezing microtome (Leica Microsystems Co., Ltd., Shanghai, China), and stained with haematoxylin and eosin (Nabuurs et al., 1993). A total of ten intact, well-oriented crypt-villus units were selected for each intestinal cross-section. The villus height and the crypt depth were measured using an image processing and analysis system (Version 1, Leica Imaging Systems Co., Ltd., Cambridge, UK), and then the ratio of villus height to crypt depth (VH/CD) was calculated. Villus height was measured from the tip of the villus to villus-crypt junction and crypt depth was defined as the depth of the invagination between adjacent villi (Hou et al., 2006).

\section{Statistical analysis}

All experimental data were analyzed in accordance with the GLM Procedure established by the SAS Institutes (2003). Regression analysis was conducted to evaluate linear and quadratic effects of chitosan levels on the various parameters measured in this experiment. Experimental unit was the replicate for all analysis. The BWG data were further analyzed by broken-line analysis to determine the optimal level of chitosan supplementation (Liu et al., 2008). The variability of the data was expressed as the standard error and a probability level of $\mathrm{p}<0.05$ was considered to be 
Table 2. Effects of dietary chitosan on the growth of weaned pigs ${ }^{1}$

\begin{tabular}{|c|c|c|c|c|c|c|c|c|c|}
\hline \multirow{2}{*}{ Items } & \multirow{2}{*}{ Time } & \multicolumn{5}{|c|}{ Levels of dietary chitosan (mg/kg) } & \multirow{2}{*}{ SEM } & \multicolumn{2}{|c|}{$\mathrm{p}$-value } \\
\hline & & 0 & 100 & 500 & 1,000 & 2,000 & & Linear & Quadratic \\
\hline \multirow[t]{3}{*}{$\mathrm{BW}(\mathrm{kg})$} & $0 \mathrm{~d}$ & 11.54 & 11.49 & 11.61 & 11.57 & 11.59 & 0.130 & 0.687 & 0.891 \\
\hline & $14 \mathrm{~d}$ & 17.91 & 17.93 & 18.65 & 18.48 & 18.00 & 0.267 & 0.827 & 0.064 \\
\hline & $28 \mathrm{~d}$ & 25.77 & 26.35 & 27.34 & 27.07 & 26.20 & 0.411 & 0.763 & 0.012 \\
\hline \multirow[t]{3}{*}{ BWG (kg) } & $0-14 \mathrm{~d}$ & 6.37 & 6.44 & 7.04 & 6.91 & 6.41 & 0.204 & 0.968 & 0.013 \\
\hline & $14-28 \mathrm{~d}$ & 7.85 & 8.42 & 8.70 & 8.59 & 8.20 & 0.211 & 0.759 & 0.028 \\
\hline & $0-28 \mathrm{~d}$ & 14.23 & 14.86 & 15.74 & 15.50 & 14.61 & 0.363 & 0.839 & 0.004 \\
\hline
\end{tabular}

${ }^{1}$ The number of observations for each mean value was thirty-six $(n=36)$.

statistically significant, whereas a $\mathrm{p}<0.10$ was considered to constitute a tendency.

\section{RESULTS}

\section{Growth performance}

Effects of chitosan supplementation on growth performance of weaned pigs are shown in Table 2. Dietary supplementation of chitosan had a quadratic improving tendency $(\mathrm{p}=0.064)$ on final body weight on $\mathrm{d} 14$ and quadratic improving $(\mathrm{p}<0.05)$ on $\mathrm{d} 28$. Furthermore, dietary chitosan quadratically improved average body weight gains in the first $14 \mathrm{~d}(\mathrm{p}<0.05)$ and the second $14 \mathrm{~d}(\mathrm{p}<0.05)$. The broken-line analysis on BWG of pigs during the entire study period of $28 \mathrm{~d}$ indicated that the optimal level of chitosan supplementation was $545.1 \mathrm{mg} / \mathrm{kg}$ (Figure 1).

\section{Serum GH and IGF-I}

Effects of chitosan supplementation on serum GH and IGF-I of weaned pigs are shown in Table 3. Dietary supplementation of chitosan tended to quadratically increase the concentration of serum GH on $\mathrm{d} 14(\mathrm{p}=0.082)$ and $28(\mathrm{p}=0.087)$. However, there was no effect on serum IGF-1 with increasing chitosan supplementation.

\section{Small intestinal morphological structure}

Effects of chitosan supplementation on small intestinal morphological structure of weaned pigs are shown in Table 4. Dietary chitosan quadratically increased the ratio of villus height to crypt depth in duodenum on $d 14(\mathrm{p}<0.05)$ and $28 \quad(\mathrm{p}<0.01)$, meanwhile, quadratically decreased $(\mathrm{p}<0.01)$ crypt depth in duodenum on $\mathrm{d} 22$. Diets supplemented with increasing levels of chitosan increased quadratically the villus height of jejunum on $\mathrm{d} 14$ ( $\mathrm{p}=$ $0.089)$ and $28(\mathrm{p}=0.074)$, and the ratio of villus height to crypt depth on $\mathrm{d} 14(\mathrm{p}=0.055)$ and $28(\mathrm{p}<0.01)$, however, decreased linearly $(p<0.05)$ or quadratically $(p<0.01)$ the crypt depth on $\mathrm{d} 28$. In addition, dietary chitosan quadratically increased the villus height and the ratio of villus height to crypt depth in ileum on $d 14$ ( $p<0.01$, $\mathrm{p}<0.01)$ and $28(\mathrm{p}<0.01, \mathrm{p}<0.01)$, however, linearly $(\mathrm{p}<$ $0.05)$ and quadratically $(\mathrm{p}<0.05)$ decreased crypt depth on

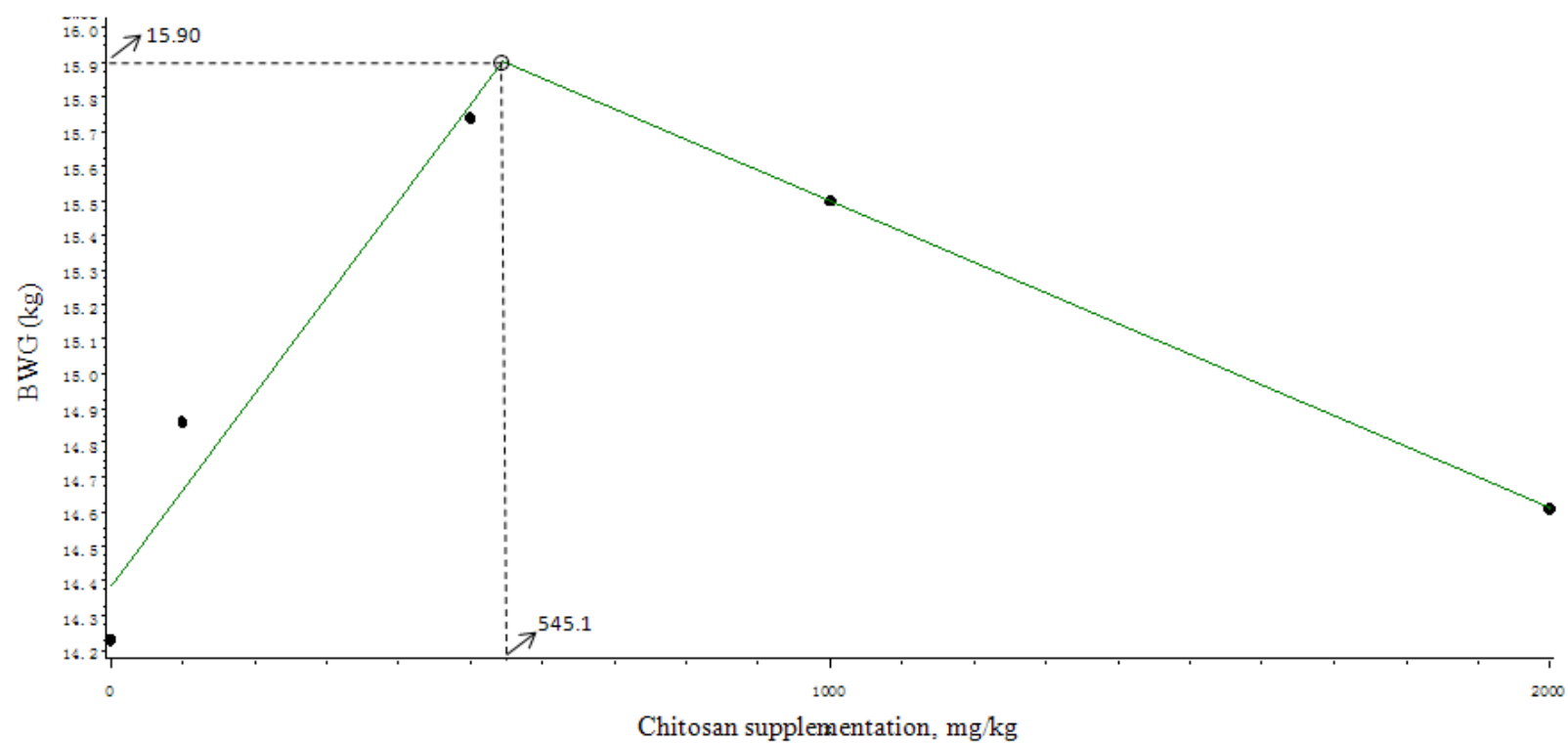

Figure 1. Broken-line analysis of BWG of pigs given diets with different levels of chitosan supplementation during the entire study period of $28 \mathrm{~d}$. The broken-line analysis indicated the breakpoint as $545.1 \mathrm{mg} / \mathrm{kg}$, showing that the maximal BWG can be obtained by supplementation of $545.1 \mathrm{mg}$ of chitosan $/ \mathrm{kg}\left(\mathrm{p}=0.006, \mathrm{R}^{2}=0.377\right)$. 
Table 3. Effects of dietary chitosan on serum GH and IGF-I in weaned pigs ${ }^{1}$

\begin{tabular}{|c|c|c|c|c|c|c|c|c|c|}
\hline \multirow{2}{*}{ Item } & \multirow{2}{*}{ Age } & \multicolumn{5}{|c|}{ Levels of dietary chitosan $(\mathrm{mg} / \mathrm{kg})$} & \multirow{2}{*}{ SEM } & \multicolumn{2}{|c|}{ p-value } \\
\hline & & 0 & 100 & 500 & 1,000 & 2,000 & & Linear & Quadratic \\
\hline \multirow[t]{2}{*}{$\mathrm{GH}(\mathrm{ng} / \mathrm{mL})$} & $14 \mathrm{~d}$ & 4.410 & 4.705 & 5.035 & 4.694 & 4.505 & 0.15 & 0.565 & 0.082 \\
\hline & $28 \mathrm{~d}$ & 4.266 & 4.366 & 4.806 & 4.440 & 4.187 & 0.15 & 0.401 & 0.087 \\
\hline \multirow[t]{2}{*}{ IGF-1 (ng/mL) } & $14 \mathrm{~d}$ & 152.601 & 155.381 & 166.699 & 156.385 & 152.979 & 10.14 & 0.802 & 0.747 \\
\hline & $28 \mathrm{~d}$ & 156.640 & 158.775 & 160.164 & 158.679 & 157.733 & 10.72 & 0.995 & 0.980 \\
\hline
\end{tabular}

${ }^{1}$ The number of observations for each mean value was six $(n=6)$.

d 14 and quadratically $(\mathrm{p}<0.05)$ decreased crypt depth on d 28 .

\section{DISCUSSION}

The weaning period is one of the most stressful phases after birth with weaning process inducing digestive disorder, intestinal barrier dysfunctions and impaired performance (Smith et al., 2010; Peace et al., 2011; Kim et al., 2012). An improvement in pig growth performance for economic purposes can be achieved by enhancing growth rate. One of the strategies to reduce weanling stress is to provide a specific feed additive, such as chitosan. In the current study, chitosan was effective in increasing weight gain of weaned pigs, which was in agreement with established literature (Huang et al., 2005; Shi et al., 2005; Khambualai et al., 2009; Yuan and Chen, 2012).

Growth in pigs is regulated in large part by the brain neuroendocrine GH-IGFs axis (Hall et al., 1986). GH can influence skeletal and muscle growth via direct and indirect effects on protein, lipid and carbohydrate metabolism (Pell and Bates, 1990) and fulfills its function of growth promotion through improving the production of IGF-I. IGF-I can stimulate amino acid uptake and protein synthesis in muscles and can greatly reduce the rate of protein breakdown within muscle fibers (Liu et al., 2008). Tang et al. (2005) reported that dietary supplementation of chitosan increased the serum GH and IGF-I levels. As shown in present study, the weaned piglets fed the diets supplemented with increasing levels of chitosan had a quadratic increase tendency in serum GH concentration compared with the control group, but there was no difference in the concentration of serum IGF-1 among treatments. The causes of this result are unclear and requires further experimentation to solve.

The small intestine is the main place for digestion and absorption of nutrients, and the intestinal mucosa plays an important role in these processes. Weanling stress can result in relatively quick changes in the intestinal mucosa morphological structure, which lead to a reduction in villus height and an increase in crypt depth (Hampson, 1986; Pluske et al., 1996a, b). Abnormal intestinal morphological

Table 4. Effects of dietary chitosan on small intestinal morphological structure in weaned pigs ${ }^{1}$

\begin{tabular}{|c|c|c|c|c|c|c|c|c|c|c|}
\hline \multirow{2}{*}{ Item } & \multirow{2}{*}{ Age } & & \multicolumn{5}{|c|}{ Levels of dietary chitosan $(\mathrm{mg} / \mathrm{kg})$} & \multirow{2}{*}{ SEM } & \multicolumn{2}{|c|}{ p-value } \\
\hline & & & 0 & 100 & 500 & 1,000 & 2,000 & & Linear & Quadratic \\
\hline \multirow[t]{6}{*}{ Duodenum } & $14 \mathrm{~d}$ & Villus height (um) & 501.69 & 510.43 & 535.50 & 524.87 & 508.56 & 13.91 & 0.912 & 0.279 \\
\hline & & Crypt depth (um) & 443.29 & 431.66 & 398.24 & 427.44 & 439.81 & 12.71 & 0.731 & 0.211 \\
\hline & & $\mathrm{VH} / \mathrm{CD}^{2}$ & 1.14 & 1.18 & 1.35 & 1.23 & 1.16 & 0.05 & 0.782 & 0.040 \\
\hline & $28 \mathrm{~d}$ & Villus height (um) & 496.48 & 505.54 & 554.08 & 508.23 & 497.27 & 17.94 & 0.725 & 0.224 \\
\hline & & Crypt depth (um) & 474.07 & 465.96 & 411.01 & 434.34 & 469.86 & 12.44 & 0.996 & $<0.001$ \\
\hline & & $\mathrm{VH} / \mathrm{CD}^{2}$ & 1.05 & 1.09 & 1.35 & 1.17 & 1.06 & 0.06 & 0.822 & 0.006 \\
\hline \multirow[t]{6}{*}{ Jejunum } & $14 \mathrm{~d}$ & Villus height (um) & 533.41 & 549.04 & 574.02 & 564.89 & 534.81 & 12.84 & 0.597 & 0.089 \\
\hline & & Crypt depth (um) & 389.54 & 355.26 & 340.99 & 365.72 & 376.18 & 16.30 & 0.769 & 0.413 \\
\hline & & $\mathrm{VH} / \mathrm{CD}^{2}$ & 1.37 & 1.57 & 1.68 & 1.57 & 1.42 & 0.08 & 0.521 & 0.055 \\
\hline & $28 \mathrm{~d}$ & Villus height (um) & 473.75 & 528.36 & 567.22 & 496.94 & 485.04 & 18.85 & 0.302 & 0.074 \\
\hline & & Crypt depth (um) & 415.46 & 411.51 & 367.88 & 375.43 & 378.11 & 11.34 & 0.013 & 0.006 \\
\hline & & $\mathrm{VH} / \mathrm{CD}^{2}$ & 1.14 & 1.29 & 1.54 & 1.33 & 1.28 & 0.07 & 0.624 & 0.008 \\
\hline \multirow[t]{6}{*}{ Ileum } & $14 \mathrm{~d}$ & Villus height (um) & 373.80 & 410.67 & 457.47 & 421.18 & 364.67 & 18.35 & 0.198 & 0.001 \\
\hline & & Crypt depth (um) & 336.90 & 309.93 & 286.60 & 337.78 & 359.11 & 15.41 & 0.025 & 0.025 \\
\hline & & $\mathrm{VH} / \mathrm{CD}^{2}$ & 1.12 & 1.33 & 1.61 & 1.25 & 1.02 & 0.10 & 0.040 & 0.001 \\
\hline & $28 \mathrm{~d}$ & Villus height (um) & 370.64 & 415.26 & 442.17 & 438.65 & 424.47 & 15.42 & 0.103 & 0.009 \\
\hline & & Crypt depth (um) & 373.08 & 337.41 & 315.68 & 349.86 & 371.61 & 11.52 & 0.335 & 0.034 \\
\hline & & $\mathrm{VH} / \mathrm{CD}^{2}$ & 0.99 & 1.23 & 1.40 & 1.26 & 1.14 & 0.07 & 0.690 & 0.006 \\
\hline
\end{tabular}

${ }^{1}$ The number of observations for each mean value was six $(n=6) .{ }^{2} \mathrm{VH} / \mathrm{CD}$ means the ratio of villus height to crypt depth. 
structure is usually associated with retarded growth of weanling piglets. A shortening of the villus decreases the surface area for nutrient absorption, which lead to poor nutrient absorption and reduced performance (Xu et al., 2003). The crypt is the area where stem cells divide to permit the renewal of the villus, and a large crypt indicates fast tissue turnover and a high demand for new tissue (Hu et al., 2012). The ratio of villus height to crypt depth is a useful criterion for estimating the digestive capacity in the small intestine (Montagne et al., 2003). In agreement with the improved performance in weanling piglets, chitosan resulted in an improvement of intestinal morphological structure, as indicated by the increased small intestinal villus height and the ratio of villus height to crypt depth, and the decreased small intestinal crypt depth of weaned pigs in this study. Similar results were also reported by other investigators (Torzsas et al., 1996; Han et al., 2012). It is well known that pathogenic germs such as coliforms can destroy the normal morphology of small intestinal mucosa. Our previous study indicated that dietary chitosan could inhibit the proliferation of $E$. coli in the intestine, and improve gut microecology (Xu et al., 2012). Furthermore, chitosan provided a beneficial environment for the proliferation of enterocytes, preventing intestinal atrophy (Han et al., 2012). These studies showed that chitosan was an effective polysaccharide in ameliorating intestinal structure and function, which may be one of the reasons for the increased growth performance in weaned pigs treated with chitosan.

From the results of this study, it can be concluded that chitosan supplementation in diets of weaned pigs is helpful in improving growth rate, and the improvement mechanism may be partly attributed to increased GH concentration in serum and ameliorated morphological structure of small intestine. The optimal response occurred at $500 \mathrm{mg} / \mathrm{kg}$.

\section{ACKNOWLEDGEMENTS}

This research was supported by National Natural Science Foundation, China (Project No. 31060310).

\section{REFERENCES}

Benhabiles, M. S., R. Salah, H. Lounici, N. Drouiche, M. F. A. Goosen, and N. Mameri. 2012. Antibacterial activity of chitin, chitosan and its oligomers prepared from shrimp shell waste. Food Hydrocoll. 29:48-56.

Crini, G. 2005. Recent developments in polysaccharide-based materials used as absorbents in wastewater treatment. Prog. Polym. Sci. 30:38-70.

Dai, T., G. P. Tegos, M. Burkatovskaya, A. P. Castano, and M. R. Hamblin. 2009. Chitosan acetate bandage as a topical antimicrobial dressing for infected burns. Antimicrob. Agents Chemother. 53:393-400.
Goiri, I., L. M. Oregui, and A. Garcia-Rodriguez. 2010. Use of chitosans to modulate ruminal fermentation of a 50:50 forageto-concentrate diet in sheep. J. Anim. Sci. 88:749-755.

Hall, T. R., S. Harvey, and C. G. Scanes. 1986. Control of growth hormone secretion in the vertebrates: a comparative survey. Comp. Biochem. Physiol. 84A:231-253.

Hampson, D. J. 1986. Alterations in piglet small intestinal structure at weaning. Res. Vet. Sci. 40:32-40.

Han, X. Y., W. L. Du, Q. C. Huang, Z. R. Xu, and Y. Z. Wang. 2012. Changes in small intestinal morphology and digestive enzyme activity with oral administration of copper-loaded chitosan nanoparticles in rats. Biol. Trace Elem. Res. 145:355360

Hou, Y. Q., Y. L. Liu, J. Hu, and W. H. Shen. 2006. Effects of lactitol and tributyrin on growth performance, small intestinal morphology and enzyme activity in weaned pigs. Asian-Aust. J. Anim. Sci. 19:1470-1477.

Huang, R. L., Y. L. Yin, G. Y. Wu, Y. G. Zhang, T. J. Li, L. L. Li, M. X. Li, Z. R. Tang, J. Zhang, B. Wang, J. H. He, and X. Z. Nie. 2005. Effect of dietary oligochitosan supplementation on ileal digestibility of nutrients and performance in broilers. Poult. Sci. 84:1383-1388.

Huang, R. L., Y. L. Yin, M. X. Li, G. Y. Wu, T. J. Li, L. L. Li, C. B. Yang, J. Zhang, B. Wang, Z. Y. Deng, Y. G. Zhang, Z. R. Tang, P. Kang, and Y. M. Guo. 2007. Dietary oligochitosan supplementation enhances immune status of broilers. J. Sci. Food Agric. 87:153-159.

Hu, C. H., L. Y. Gu, Z. S. Luan, J. Song, and K. Zhu. 2012. Effects of montmorillonite-zinc oxide hybrid on performance, diarrhea, intestinal permeability and morphology of weanling pigs. Anim. Feed Sci. Technol. 177:108-115.

Khambualai, O., K. Yamauchi, S. Tangtaweewipat, and B. ChevaIsarakul. 2009. Growth performance and intestinal histology in broiler chickens fed with dietary chitosan. Br. Poult. Sci. 50: 592-597.

Kim, J. C., C. F. Hansen, B. P. Mullana, and J. R. Pluske. 2012. Nutrition and pathology of weaner pigs: nutritional strategies to support barrier function in the gastrointestinal tract. Anim. Feed Sci. Technol. 173:3-16.

Knaul, J. Z., S. M. Hudson, and K. A. M. Creber. 1999. Crosslinking of chitosan fibers with dialdehydes: Proposal of a new reaction mechanism. J. Polym. Sci. Part B, Polym. Phys. 37:1079-1094.

Koide, S. S. 1998. Chitin-chitosan: properties, benefits and risks. Nutr. Res. 18:1091-1101.

Li, H. Y., S. M. Yan, B. L. Shi, and X. Y. Guo. 2009. Effect of chitosan on nitric oxide content and inducible nitric oxide synthase activity in serum and expression of inducible nitric oxide synthase mRNA in small intestine of broiler chickens. Asian-Aust. J. Anim. Sci. 22:1048-1053.

Liao, F. H., M. J. Shieh, N. C. Chang, and Y. W. Chien. 2007. Chitosan supplementation lowers serum lipids and maintains normal calcium, magnesium, and iron status in hyperlipidemic patients. Nutr. Res. 27:146-151.

Limam, Z., S. Selmi, S. Sadok, and A. El-abed. 2011. Extraction and characterization of chitin and chitosan from crustacean byproducts: biological and physicochemical properties. Afr. J. Biotechnol. 10:640-647. 
Liu, G. M., Y. Wei, Z. S. Wang, D. Wu, and A. G. Zhou. 2008. Effects of dietary supplementation with cysteamine on growth hormone receptor and insulin-like growth factor system in finishing pigs. J. Agric. Food Chem. 56:5422-5427.

Liu, P., X. S. Piao, S. W. Kim, L. Wang, Y. B. Shen, H. S. Lee, and S. Y. Li. 2008. Effects of chito-oligosaccharide supplementation on the growth performance, nutrient digestibility, intestinal morphology, and fecal shedding of Escherichia coli and Lactobacillus in weaning pigs. J. Anim. Sci. 86:2609-2618.

Moon, J. S., H. K. Kim, H. C. Koo, Y. S. Joo, H. M. Nam, Y. H. Park, and M. I. Kang. 2007. The antibacterial and immunostimulative effect of chitosan-oligosaccharides against infection by staphylococcus aureus isolated from bovine mastitis. Appl. Microbiol. Biotechnol. 75:989- 998.

Montagne, L., J. R. Pluske, and D. J. Hampson. 2003. A review of interactions between dietary fibre and the intestinal mucosa, and their consequences on digestive health in young nonruminant animals. Anim. Feed Sci. Technol. 108:95-117.

Nabuurs, M. J. A., A. Hoogendoorn, E. J. Van Der Molen, and A. L. M. Van Osta. 1993. Villus height and crypt depth in weaned and unweaned pigs, reared under various circumstances in the Netherlands. Res. Vet. Sci. 55:78-84.

NRC. 1998. Nutrient requirements of swine. 10th ed. National Academic Press, Washington, DC.

Peace, R. M., J. Campbell, J. Polo, J. Crenshaw, L. Russell, and A. J. Moeser. 2011. Spray-dried porcine plasma influences intestinal barrier function, inflammation, and diarrhea in weaned pigs. J. Nutr. 141:1312-1317.

Pell, J. M., and P. C. Bates. 1990. The nutritional regulation of growth hormone action. Nutr. Res. Rev. 3:163-192.

Pluske, J. R., I. H. Williams, and F. X. Aherne. 1996a. Maintenance of villus height and crypt depth in piglets by providing continuous nutrition after weaning. Anim. Sci. 62: 131-144.

Pluske, J. R., I. H. Williams, and F. X. Aherne. 1996b. Villus height and crypt depth in piglets in response to increases in the intake of cows' milk after weaning. Anim. Sci. 62:145-158.

Pusateri, A. E., J. B. Holcomb, B. S. Kheirabadi, H. B. Alam, C. E.Wade, and K. L. Ryan. 2006. Making sense of the preclinical literature on advanced hemostatic products. J. Trauma-Injury Infection and Critical Care 60:674-682.

SAS. 2003. SAS user's guide: Statistics. Version 9.0. SAS Institute., Cary, NC.

Shi, B. L., D. F. Li, X. S. Piao, and S. M. Yan. 2005. Effects of chitosan on growth performance and energy and protein utilisation in broiler chickens. Br. Poult. Sci. 46:516-519.
Smith, F., J. E. Clark, B. L. Overman, C. C. Tozel, J. H. Huang, J. E. Rivier, A. T. Blisklager, and A. J. Moeser. 2010. Early weaning stress impairs development of mucosal barrier function in the porcine intestine. Am. J. Physiol. Gastrointest. Liver Physiol. 298:352-363.

Tang, Z. R., Y. L. Yin, C. M. Nyachoti, R. L. Huang, T. J. Li, C. B. Yang, X. J. Yang, J. Gong, J. Peng, D. S. Qi, J. J. Xing, Z. H. Sun, and M. Z. Fan. 2005. Effect of dietary supplementation of chitosan and galacto-mannan-oligosaccharide on serum parameters and the insulin-like growth factor-I mRNA expression in early-weaned piglets. Domest. Anim. Endocrinol. 28:430-441.

Torzsas, T. L, C. W. Kendall, M. Sugano, Y. Iwamoto, and A. V. Rao. 1996. The influence of high and low molecular weight chitosan on colonic cell proliferation and aberrant crypt foci development in CF1 mice. Food Chem. Toxicol. 34:73-77.

Tsukada, K., T. Matsumoto, K. Aizawa, A. Tokoro, R. Naruse, S. Suzuki, and M. Suzuki. 1990. Antimetastatic and growthinhibitory effects of $\mathrm{N}$-acetylchitohexaose in mice bearing Lewis lung carcinoma. Jpn. J. Cancer Res. 81:259-265.

Wang, S. Q., and C. S. Zhang. 2004. Chitin, chitosan and their applications in aquaculture. Feed Res. 5:25-28.

Xu, C. L., and Y. Z. Wang. 2005. The applications of chitin in aquaculture. China Feed. 7:30-32.

Xu, Y. Q., B. L. Shi, J. L. Li, T. Y. Li, Y. W. Guo, L. X. Tian, X. Z. $\mathrm{Fu}$, and L. Hong. 2012. Effects of chitosan on intestinal flora in weaned pigs. Feed Res. 10:54-56.

Xu, Z. R., C. H. Hu, M. S. Xia, X. A. Zhan, and M. Q. Wang. 2003. Effects of dietary fructooligosaccharide on digestive enzyme activities, intestinal microflora and morphology of male broilers. Poult. Sci. 82:1030-1036.

Yao, H. T., S. Y. Huang, and M. T. Chiang. 2006. Effect of chitosan on plasma cholesterol and glucose concentration in streptozotocin-induced diabetic rats. Taiwan J. Agric. Chem. Food Sci. 44:122-132.

Yao, H. T., S. Y. Huang, and M. T. Chiang. 2008. A comparative study on hypoglycemic and hypocholesterolemic effects of high and low molecular weight chitosan in streptozotocininduced diabetic rats. Food Chem. Toxicol. 46:1525-1534.

Yin,Y. L., Z. R. Tang, Z. H. Sun, Z. Q. Liu, T. J. Li, R. L. Huang, Z. Ruan, Z. Y. Deng, B. Gao, L. X. Chen, G. Y. Wu, and S. W. Kim. 2008. Effect of galacto-mannan-oligosaccharides or chitosan supplementation on cytoimmunity and humoral immunity response in early-weaned piglets. Asian-Aust. J. Anim. Sci. 21:723-731.

Yuan, S. B., and H. Chen. 2012. Effects of dietary supplementation of chitosan on growth performance and immune index in ducks. Afr. J. Biotechnol. 11:3490-3495. 